\title{
De-colonising Architectural Education: Thoughts from Cape Town
}

\author{
Tomá Berlanda \\ School of Architecture, Planning and Geomatics, University of Cape Town, Cape Town, South Africa \\ Email: toma.berlanda@uct.ac.za
}

\begin{abstract}
The paper reflects on the condition of architectural education and practice in Sub-Saharan Africa, where most educational models were imported from, when not even imposed by, colonising countries. This lasting self-referential condition is further enforced by professional bodies, which, as it the case across 13 English speaking African countries, still use the reference to the criteria set forth by the Commonwealth Association of Architects for their validation protocols. If this legacy in the built form has attracted interest from abroad, insufficient attention has been given to the need for reconceptualising curricula to allow for a plurality of different voices to be heard. Educating architects is predominantly seen as training in response to the demand for professionals. Institutions of Higher Education are largely complicit with the situation and are unwilling to push for systemic reform of the system. But surely the intersection of social, racial and class inequality that is integral to many countries in Southern Africa offers the opportunity to challenge the notion that University is itself' 'one of the oldest surviving institutions in the Western world [and it] has colonised the globe. The paper argues for the need to develop educational frameworks that explicitly question both the scholarly excellence of the imported models, and the discrepancy between the formal aesthetics and the material living conditions of the people affected by the transformation of landscape and territory.
\end{abstract}

KEYWORDS architecture, education, Sub-Saharan Africa

Received June 30, 2017; accepted July 7, 2017.

For a European architect and scholar that has been working in Sub-Saharan African countries for the last seven years, any reflection on the notion and practice of 'architecture and built heritage' is inevitably linked to the understanding of who holds power. That means coming to terms with who, within any given cultural, social and political context, holds the authority to decide which traces of the past are considered worthy of the collective memory, and hence of preservation.

If this can be easily understood as a way to describe the situation for countries that are under a colonial rule, or, as it is more often referred to today, are open to 'foreign investments for development', the Sub-Saharan African situation is a paradigmatic example of the arbitrary criteria used both from those who consider Africa as one whole site of rich heritage whose histories ought to be 'valorised', and from those who consider them irrelevant. The result is that, notwithstanding the diffused rhetoric on the potential reciprocal enrichment derived from the encounter between different cultures, heritage is the object of appropriation and removal.

This state of affairs has changed ever so slightly in current times, as traditional colonial powers have been flanked by the massive and growing presence of Chinese interventions. These have set in motion large territorial transformations that have been criticised for their lack of sensitivity towards the local cultures. The examples that have hit the news are the construction of new cities next to Luanda, Angola (Onishi, 2017), or the scheme for Modderfontein CBD \& Gateway Precinct Plan in Johannesburg, South Africa.

Amongst the many reasons that lay behind the acceptance-when not outright encouragement-by African elites of almost any intervention that is presented as a form of modernisation, one that seems to me to hold particular significance is the state of the educational system for professional architects. It is clear that how a society selects, classifies, distributes, transmits and evaluates the 
educational knowledge, reflects both the distribution of power and the principle of social control. In the case of architectural education, one has to note that this is too often translated in the lack of an endogenous process of discovery, of architectural discovery, of the way space is inhabited.

Even though exactly 60 years have elapsed since Ghana's independence (March 6, 1957), that led to the unravelling of colonialism in Sub-Saharan Africa. By and large, the educational offerings in the continent, at every level from primary to tertiary education, still reproduce models introduced by foreign powers during the colonial era.

Outside of South Africa, where architectural education was first introduced in 1921, the first school of architecture was established in Kumasi, Ghana, precisely in 1957. Following the steps of what had happened in South Africa, architects as professionals, had either been trained abroad at universities such as Liverpool, the Architectural Association in London or the Bauhaus or they, had trained as apprentices in local architectural firms (Papanicolau, 2006).

In Great Britain in particular, the topic of building in the tropics was intensely discussed in academic circles around the early 1950s and had significant repercussions in practice. A large conference on tropical architecture, organised by Otto Konigsberger, was held in 1953 at the University College of London, and it led, in 1954, to the establishment at the Architectural Association of the postgraduate program for tropical architecture. The first director was Maxwell Fry, an architect that together with his wife Jane Drew had been already active in the years immediately after World War II in West Africa. The program attracted students from Great Britain as well from all over the world and proved to be extremely influential. It still exists today under the name Development Planning Unit at the Bartlett School of Architecture. Its mission is to 'conduct world-leading research and postgraduate teaching that helps to build the capacity of national governments, local authorities, NGOs, aid agencies and businesses working towards socially just and sustainable development in the global south' (DPU, 2017). In the words they used to celebrate their $50^{\text {th }}$ anniversary back in 2004 'the Department set out to influence the Eurocentric architecture that was being exported to the tropics by introducing elements of medical research and building physics to appropriate climatic design. The functionalist ideals of the modern movement made it receptive to such innovation and the Department's influence took root' (Wakely 2014, 7), no mention is made of the cultural or social issue.
The legacy of this influence is still visible in how curricula are mostly modelled on those of European or American universities, and a large portion of faculty and academics have undergone experiences abroad. This, coupled with the fact that the initial cohort of the staff had to be trained in foreign institutions, has created a selfreferential model, which is hard to break.

The nefarious consequences of this framework, such as environmentally inappropriate and inefficient buildings, design for cities that reproduce slogans and schemes that are ill at ease with the economic and social conditionsrarely leads to a challenge of the strategies and educational programs devised by governments, and often supported and hailed as models by international organisations, although at the very least something is changing in the rhetoric of the message.

The comparison between the editorial of the 1952 issue of Architectural Record dedicated to Building in the Tropics, and the editorial of the 2013 Docomomo Journal on modern Africa is elucidating. The first reminds us that: 'Building for the tropics must meet the same kind of problems as clothing for the tropics. We don't entirely [want to?] "go native" in either instance. ... it may prove to be a heavy burden if we aren't sensible about it.' (Rannells 1952, 153) Whereas the second claims how 'With the introduction of postcolonial theory in the historiography of architecture, an exclusively ideological critical sense has been developed preventing disciplinary autonomy or practice of architecture and finally condemning any objective look. ... The recognition that a widespread awareness of Modern Movement architecture has always been serving colonisation involves rethinking the basic principle of Modern welfare society and practised architecture as a mission.' (Tostões 2013, 2)

Simultaneously, what the excerpts suggest is that one is confronted with a renewed expansion and strengthening of the cultural dominion of the Global North, which is both a premise and a corollary to the economic oversight and control, but through much subtler means.

Similar concepts had been expressed by two architects, Athina Saviddu and Luciano Barbero, who had ventured in Sub-Saharan Africa in the early 1970s asking themselves: "what kind of "culture" is appropriate in a society that wants to get rid of neo-capitalistic control ... A choice has to be made between the interest of the institutional power and those of the population, between the imposition of an imported model and the painstaking research for solutions that take into account the meaning and consequences of the problems' (Barbero and Saviddu 1981, 117). 
Another testimony from 40 years ago, further proof of the non-novelty of the issue, is one by William Bechhoefer. In a piece he authored on 'architectural education in developing nations', building on his experience as peace corps volunteer in Tunisia in the late 1960s, and later as a lecturer and acting chairman at the Department of Architecture in Kabul between 1973 and 1974, he notes that 'the role of an architect in a developing nation and the structuring of architectural education are problems closely related to the goals of that nation's society. As a consequence, the inevitable participation of foreign technicians in these programs raises questions as to the nature of that participation and the extent to which it can be effective' (Bechhoefer 1977, 19).

Now there is no doubt about the intrinsic relationship between architecture and power, and the weight of this heritage in the built form attracts growing interest from the Global North, as is evidenced by the research and exhibition projects such as 'African Modernism' (Herz, 2015). However, the growing number of studies that documents the situation with reference to different disciplines, mostly constrain themselves to merely identifying the hurdles that prevent the necessary change, whilst on the contrary insufficient attention is given to the need to reconceptualise architectural education in the continent to allow for a plurality of different voices to be heard.

Notable exceptions are present, but they tend to be marginalised and ostracised by professional and accrediting bodies. Suffice it to say that across 13 English speaking countries in Sub-Saharan Africa, the reference model for validating a professional architectural degree is still today the one set forth in the so called 'Green Book' by the Commonwealth Association of Architects.

The result is that the role of architecture within education is predominantly seen as the production of built form. Institutions of Higher Education are largely complicit with the situation and are unwilling to push for systemic reform of the system. In fact, recently the argument has been made that University itself is 'one of the oldest surviving institutions in the Western world. It has colonised the globe, its architecture reflecting the prevailing ideology - of which it is the reproductive machinery' (Wilkinson 2015, 37).

What we thus see is a widening gap between an architectural history that is increasingly more interested in culture, context, and politics and an architectural production that is almost completely indifferent to critically question what defines the urban condition, particularly beyond the seduction of the notion of 'African city'.
Adapting the education to changes in society and a critical review of the accepted conventions governing the content and organisation of knowledge in a discipline is not an easy task. A precondition is to identify and confront those educational experiences that explicitly challenge both the 'scholarly superiority' of the imported models and the discrepancy between the formal aesthetics and the material living conditions of the people affected by the transformation of landscape and territory. Amongst the attempts that go in this direction, it is worth mentioning the role of research and practice platforms and networks such as the African Centre for Cities at the University of Cape Town, ArchiAfrika, and Folio, a new magazine that wants to be 'modern|critical|African', recently launched by the Graduate School of Architecture in Johannesburg.

These works tangibly stem from the recognition that education for sustainability implies accepting the principle that the architect's fundamental responsibility is an ethical one (Eldeen 2004), and what they share is a commitment to help students to develop responsive architectural solutions to the social, economic and environmental realities facing the built environment.

Within the architectural curriculum, the strand that has been mostly challenged is the teaching of 'Architectural History and Theory'. In a number of papers multiple questions have been raised around non-Western approaches to a global history of the built form. Of particular relevance is the contribution by Ikem Okoye (2002) who, on the basis of an accurate survey of the situation in Ethiopia, Ghana, Nigeria and South Africa, shows how the modalities of teaching architectural history across different universities reflects very different conceptions of history, and of the disciplinary nature of architecture itself. From an operative standpoint, the issues that appear to be more relevant to him, deal with highlighting the differences in teaching method between history and architectural history, the risks that derive from the diffused tendency of unifying the courses of history and theory of architecture, and most of all from considering the teaching of architectural history as ancillary, or otherwise functional to the 'studio' based teaching.

Okoye (2002) further addresses the complex issue of how to materialise the principled intentions around the need of shifting the teaching focus to include materials and topics that narrate the building experiences of 'Africans'. Not a simple operation, given in the continent every language community has an architectural history. Hence, who will choose what groups of narratives, that is what 
ethnic groups will be represented, what weight will oral tradition have, which will the influence be of the Western literature on vernacular architecture, and the examples proposed?

These same questions are valid also today, and if, possible, even more pressing, at a time where multiple universities reduce funds and resources available to humanities and history programmes in general, and one can register some form of hostility on the part of students which are led by webzines to identify modernity with the works of global archistars.

Moreover, the implications of the debate on the teaching of architectural history outside academia are becoming increasingly evident, in particular amongst professionals and public officers in charge of built heritage. It is a situation that can be observed in many places, but that in South Africa is even more conflicting since the white hegemonic legacy has historically imposed the choice of what constitutes 'heritage' following a colonial epistemological construct, rather than validating local forms of history. This situation has not ceased since the end of apartheid and is in fact exacerbated by the growing tendency of considering heritage isolated from history and context and as mere objects to valorise for the tourist market. Ultimately this is a confirmation that a genuine afrocentric approach, a wide perspective that does not erase diversities but frames them within a space ripe of contestation, is a political, other than disciplinary, choice.

Curiously enough this is a debate that has also been happening in the United States, where figures like Mark Jarzombek, among others, have eloquently articulated the question in the following terms: 'If the non-West is already-always imbedded in the Western discourse, can this conceptual, geopolitical and pedagogical category of the other in turn provide an immanent critique of (non-) West from within? If so, can we, finally, overcome the West/Non-West binary?' (Jarzombek, 2012)

But is precisely in this constant falling back to the wider resonance that experiences of the North have had that lies the trap, and that leaves the space open for finally imagining new epistemologies South of the Equator.

\section{References}

Barbero, Luciano, and Saviddu Athina. 1981. "A Learning Experience in Ife University." Spazio e Società 14 (1981): 117.

Bechhoefer, William B. 1977. "Architectural Education in Developing Nations: Case Studies in Tunisia and Afghanistan." Journal of Architectural Education 30(4):
$19-22$.

The Bartlett Development Planning Unit. 2017. "About us.” Accessed June 30, 2017. https://www.ucl.ac.uk/ bartlett/development/about-us/contacts

Eldeen, Heba S. 2004. "Ethics for Architecture: Imperative Approach for Integrating Sustainable Thinking in Design Education." Paper presented at the Sustainable Architectural and Urban Design Conference, Cairo, February.

Henderson, G., and G. Holden, eds. 2007. Qualifications in Architecture Recommended for Recognition by CAA: Procedures and Criteria. United Kingdom: Commonwealth Association of Architects.

Herz, Manuel, ed. 2015. African Modernism: The Architecture of Independence: Ghana, Senegal, Côte d'Ivoire, Kenya, Zambia. Zurich: Park Books.

Jarzombek, Mark. 2012. "The Non-West in a Non-Global World." Keynote Address at The "Dis-appearing NonWest" Conference, Columbia University Graduate School of Architecture, Planning and Preservation, New York, May 4.

Okoye, Ikem, Stanley. 2002. "Architecture, History, and the Debate on Identity in Ethiopia, Ghana, Nigeria, and South Africa." Journal of the Society of Architectural Historians 61(3): 381-396.

Onishi, Norimitsu. 2017. "Angola's Corruption Boom." The New York Times, 24 June.

Papanicolau, Stella. 2006. "South African Architecture 1945-1979: The Role of Education in the Construction of Identities." Sample chapter of unfinished PhD diss., University of Cape Town.

Rannells, John. 1952. "Building in the Tropics, An Approach to the Study of Building Types Suitable for Tropical Conditions." Architectural Record 189 (1952): 153-180.

Tostões, Ana. 2013. “Ten Years After, the Continent of Hope and Modern Heritage. A Tribute to Udo Kultermann." Docomomo Journal 48: Modern Africa, Tropical Architecture: 2-3.

Wakely, Patrick. 2014. "Notes on the History of the Development Planning Unit." In Sixty Years of Urban Development, a Short History of the Development Planning Unit, edited by Patrick Wakely, Caren Levy, and Christopher, Yap, 7. London: Development Planning Unit, 2014.

Wilkinson, Tom. 2015. “Typology: University." Architectural Review 238: 36-45. 